\title{
Investigation of Nitrogen in Silicate Glasses and Iron Alloys by SXES
}

\author{
A. von der Handt ${ }^{1}$, H. Takahashi ${ }^{2}$, M. Takakura ${ }^{2}$, C. Dalou ${ }^{1}$, J. Mosenfelder $^{1}$ and M.M. Hirschmann ${ }^{1}$ \\ ${ }^{1 .}$ University of Minnesota, Department of Earth Sciences, Minneapolis, USA. \\ 2. JEOL, SA Business Unit, JEOL Ltd, Akishima Tokyo, Japan.
}

Recent innovations in electron microprobe technology include a novel type of soft-X-ray emission spectrometer (SXES) by JEOL Ltd. The SXES is composed of a CCD area detector that can be coupled to multiple varied-line-spacing (VLS) aberration-corrected gratings (JS50XL, JS200N, and JS2000) that cover a combined energy range from $50 \mathrm{eV}$ to $2.3 \mathrm{keV}$. It provides higher spectral resolution and higher sensitivity for soft $\mathrm{X}$-rays $(<1 \mathrm{keV})$ relative to traditional wavelength dispersive spectrometers (WDS), yielding information on electronic structure and bonding [1-2].

For this study we chose a series of nitrogen-bearing silicate glasses and iron alloys that were synthesized over a wide range of oxygen fugacities ( $\Delta \mathrm{IW}-3.3$ to $\Delta \mathrm{IW}-0.5)$ and pressures (1.2 to $3 \mathrm{GPa})$ [3]. Nitrogen contents ranged from 0.04 to $5.42 \mathrm{wt} \%$ in the silicate glasses and 0.98 to $3.54 \mathrm{wt} \%$ in the iron alloys. We investigated these samples by SXES at the JEOL factory and the recently installed JEOL JXA-8530FPlus with SXES at the Department of Earth Sciences, University of Minnesota (Figure 1).

Silicate glasses and iron alloys are characterized by significantly different band structure for the second order N-K lines (Figure 2). Peak positions in iron alloys are shifted toward lower energies by $1 \mathrm{eV}$ compared to the silicate glasses. Peak shapes show markers indicative of the covalent or valence bonding nature of the respective material. There are no systematic peak shifts with changes in pressure or oxygen fugacity in either the glass or alloy spectra. Although Ti contents are insignificant in both phases, the pathological interference with the second order $\mathrm{Ti}$ Ll-line can be well resolved through SXES, in contrast to WDS.

The high-energy resolution of the SXES also allows for spectroscopic mapping. Chemical state maps were acquired on samples containing three different phases: nitrogen-bearing glass, Fe-N-C alloys, and $\mathrm{Si}_{3} \mathrm{~N}_{4}$ quench crystals. Regions of interest were defined on each of the second order $\mathrm{N}-\mathrm{K}$ peak positions for the silicate glasses and the alloys. The maps help visualize the differences in nitrogen abundance and speciation between the three different phases and show the exciting potential of the SXES for EPMAbased chemical state mapping.

References:

[1] H. Takahashi et al, JEOL News 49 (2014), p. 73.

[2] M. Terauchi 2014 In: Transmission Electron Microscopy Characterization of Nanomaterials, p. 287. (Springer: Berlin, Heidelberg).

[3] C. Dalou et al, EPSL 458 (2017), p. 141. 


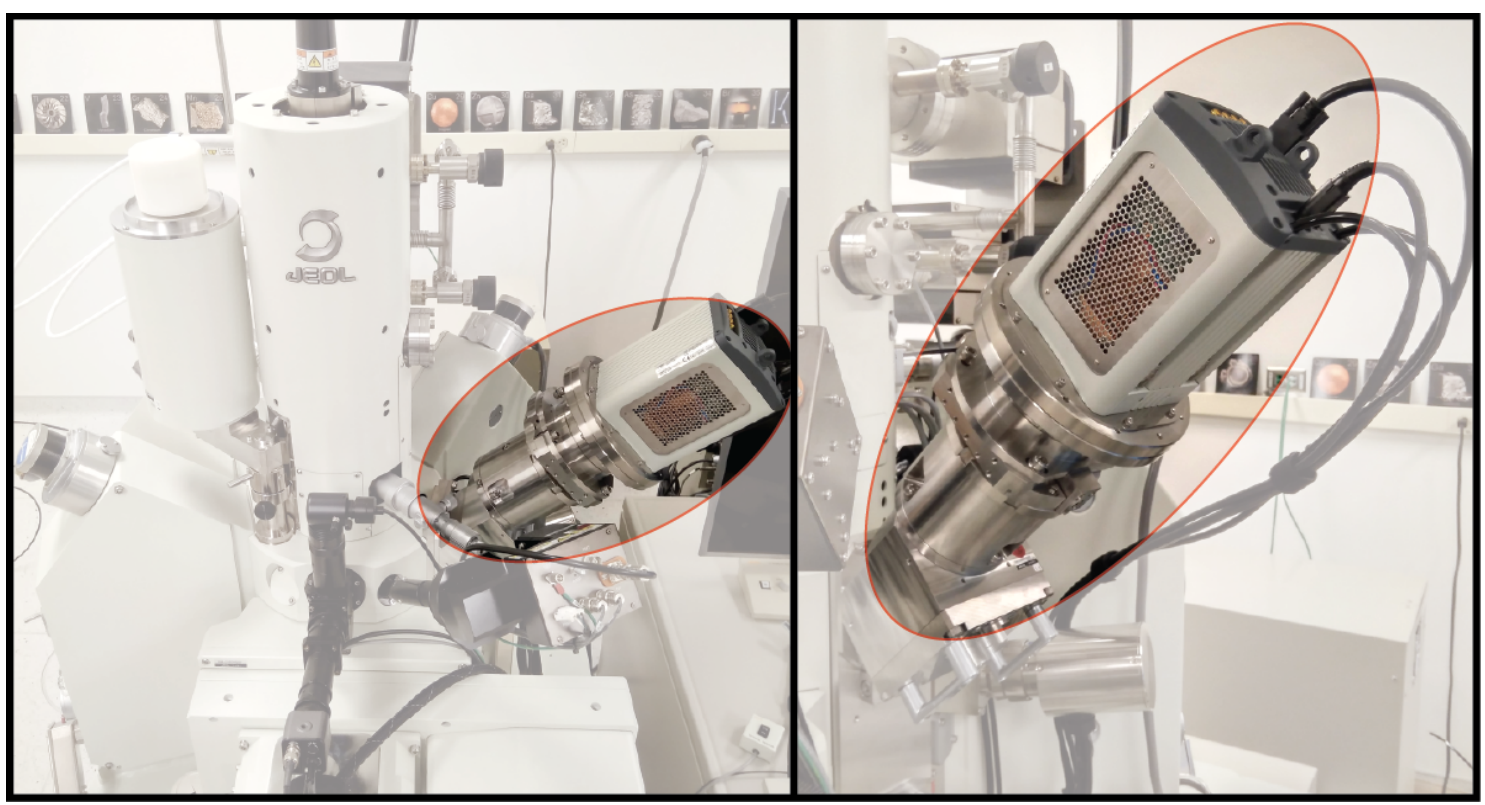

Figure 1. JEOL JXA-8530FPlus with SXES spectrometer (JS200N, JS2000) at the Department of Earth Sciences, University of Minnesota.

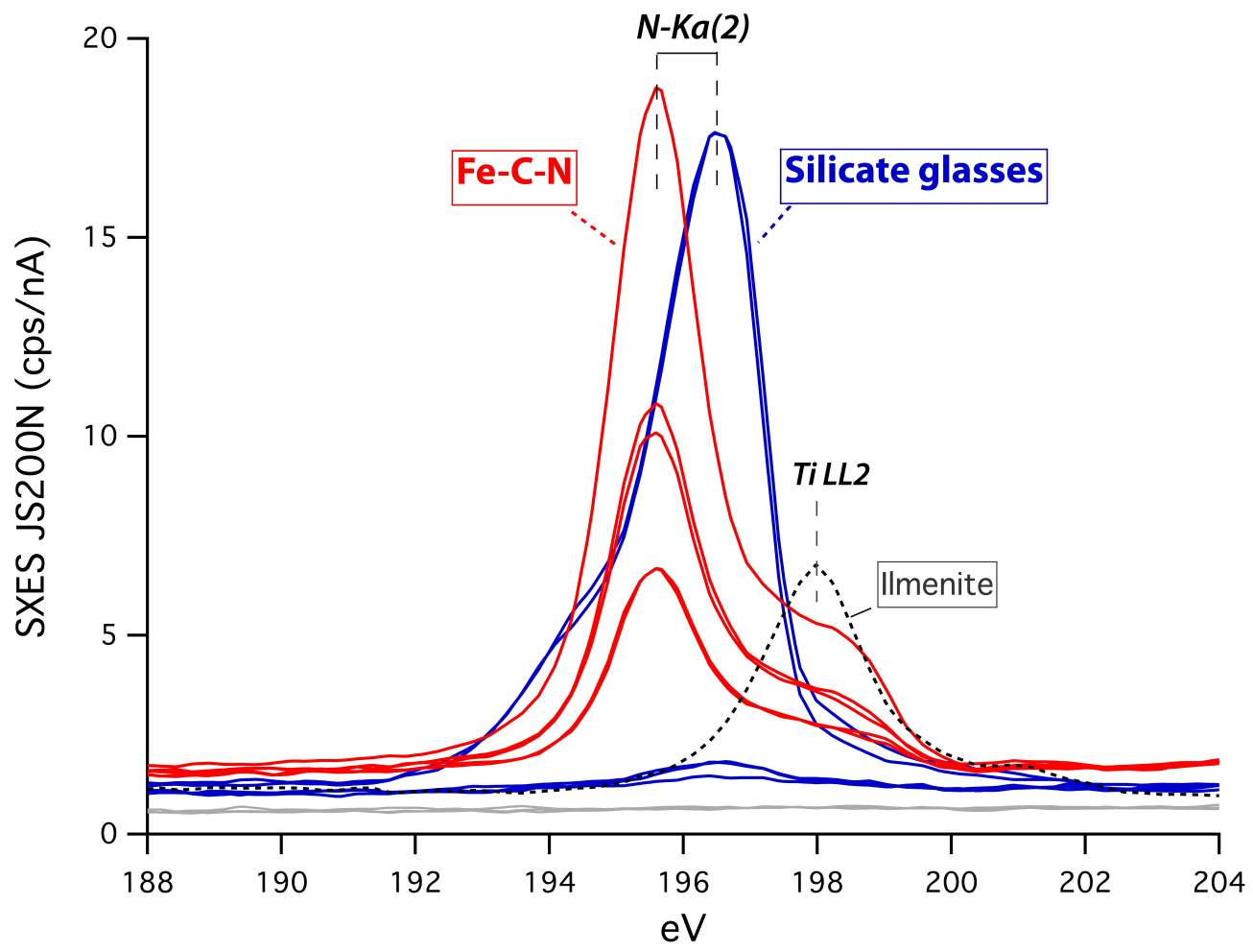

Figure 2. Comparison of soft X-ray spectra from nitrogen-bearing silicate glasses and iron alloys analyzed with the JS200N grating at $5 \mathrm{kV}, 100 \mathrm{nA}$, accumulated over 5 minutes. There is a significant peak shift between silicate glasses and alloys. Satellite bands on the high-energy side in the alloys result from conduction bands, whereas satellite bands on the low-energy side in the glasses result from valence bands. The second order Ti Ll peak (shown for ilmenite) can be well resolved from N-K(2) using SXES. 